\title{
A prática profissional nos Centros de Atenção Psicossocial II (CAPS II), na perspectiva dos profissionais de saúde mental de Santa Catarina
}

Professional practice in Psychosocial Care Centers II (CAPS II) in the perspective of mental health professionals of Santa Catarina

Fernanda Martinhago ${ }^{1}$, Walter Ferreira de Oliveira ${ }^{2}$

1 Mestre em Saúde Coletiva pela Universidade Federal de Santa Catarina (UFSC) Florianópolis (SC), Brasil.

martinhagofernanda@gmail.com

2 Doutor em Social and Philosophical Foundations of Education Program pela University of Minnesota - Twin Cities (MN), Estados Unidos. Professor do Departamento de Saúde Pública da Universidade Federal de Santa Catarina (UFSC) - Florianópolis (SC), Brasil.

walter@ccs.ufsc.br
RESUMO Trata-se de uma pesquisa de abordagem qualitativa, exploratória e descritiva, que visa a analisar a percepção dos profissionais com relação à sua prática nos Centros de Atenção Psicossocial II (CAPS II) de Santa Catarina. Os dados foram coletados nos 12 CAPS II do Estado, através de entrevistas semiestruturadas com 12 coordenadores e aplicação de questionários abertos com 24 técnicos. Os relatos foram analisados sob a ótica hermenêutico-dialética. Os resultados sugerem, a partir da percepção dos profissionais, que os CAPS II de Santa Catarina trabalham no limiar da institucionalização e que os usuários não contam com adequado suporte social e comunitário fora das instituições que prestam assistência à saúde mental.

PALAVRAS CHAVE: Centro de Atenção Psicossocial; Saúde Mental; Rede de Saúde; Intersetorialidade; Institucionalização.

ABSTRACT This is a qualitative, exploratory and descriptive study which aims to analyze the perception of professionals regarding their practice in Psychosocial Care Centers II (CAPS II) of Santa Catarina. Data were collected in the 12 CAPS II of the State, through semi-structured interviews with 12 engineers and questionnaires opened with 24 technicians. The reports were analyzed from the perspective hermeneutic-dialectic. The results suggest, from the professionals' perception, that the CAPS II Santa Catarina work on the threshold of institutionalization and that users do not have adequate social and community support outside of institutions that provide mental health care.

KEYWORDS: Psychosocial Care Center; Mental Health; Health network; intersectoriality; Institutionalization. 


\section{Introdução}

A Reforma Psiquiátrica Brasileira, iniciada no fim da década de 1970, possibilitou uma transformação na assistência à saúde mental, propondo novos espaços para os sujeitos com sofrimento psíquico intenso, que antes tinham apenas o manicômio como alternativa de 'tratamento'. Com o intuito de superar as necessidades da internação no hospital psiquiátrico, foram criados serviços substitutivos, os quais têm como proposta prestar assistência às pessoas que sofrem com transtornos mentais de maneira que possam manter um nível satisfatório de convivência e interação no contexto social.

A trajetória da reforma é repleta de discussóes sobre a assistência em saúde mental, e propiciou uma nova regulamentaçáo do funcionamento dos serviços. Em 1992, o Ministério da Saúde regulamentou os serviços de saúde mental através da Portaria no 224/MS, aprovada pelos coordenadores e assessores de saúde mental dos Estados (BRASIL, 1992). Em 2001, foi sancionada a Lei Federal no 10.216, conhecida como 'Lei da Reforma Psiquiátrica', que propóe um redirecionamento da assistência em saúde mental (BRASIL, 2001).

Os Centros de Atenção Psicossocial (CAPS) foram os primeiros serviços criados com uma nova proposta de atenção à saúde mental e incentivaram o Ministério da Saúde a regulamentar a implantação e o financiamento para ampliar os serviços por todo o País (AMARANTE, 1998). A Portaria no 336/GM, estabelecida em 2002 pelo Ministério da Saúde, redefiniu os parâmetros da Portaria no 224/92 e ampliou a abrangência dos CAPS, que passam a ser constituídos por modalidades de serviço de acordo com a abrangência populacional: CAPS I (municípios acima de 20 mil habitantes), CAPS II (entre 70 mil e 200 mil habitantes), CAPS III (acima de 200 mil habitantes), CAPSad II (acima de 70 mil habitantes) - para usuários de álcool e outras drogas - e CAPSi II (cerca de 200 mil habitantes) - voltado para crianças e adolescentes (BRASIL, 2002). Conforme a Portaria/GM no 336/02, os CAPS são estruturados para organizar a rede de atenção à saúde mental, atender diariamente a população em seu território e prestar acompanhamento clínico e reabilitação psicossocial aos sujeitos com sofrimento psíquico intenso (BRASIL, 2004a). Contam com uma equipe multidisciplinar formada por psiquiatra, psicólogo, enfermeiro, assistente social e outros profissionais, que devem prestar cuidados aos usuários através de atendimento individual e em grupos, oficinas terapêuticas, visitas domiciliares, atendimento da família e atividades comunitárias, entre outros serviços, conforme a modalidade dos CAPS.

Em 2011, foi instituída a Portaria GM no 3.088, que cria, amplia e articula pontos de atenção à saúde para pessoas com sofrimento ou transtorno mental e com necessidades decorrentes do uso de crack, álcool e outras drogas no âmbito do SUS. Essa portaria sintetiza todo o processo de rede de atenção à saúde mental, a partir da ótica do combate ao abuso de substâncias, e coloca os CAPS na categoria de atenção psicossocial especializada, vinculando-os a uma extensa rede, que inclui desde os dispositivos da atenção básica até os de emergência, atenção hospitalar e estratégias de desinstitucionalização, entre outros (BRASIL, 2011). Apesar de já em vigor, as provisóes dessa portaria, na prática, encontram-se ainda em estágio de implantação, o que nos leva a considerá-la como incipiente em sua influência sobre a prática profissional nos CAPS.

A atençáo psicossocial prestada pelos CAPS pressupóe um acolhimento dos sujeitos com sofrimento psíquico e transtorno mental, um conjunto de ações que visam à substituição da lógica manicomial como base de sustentação teórica para o cuidado em saúde mental e do modo asilar como paradigma das práticas dominantes (OLIVEIRA, 2009). Costa-Rosa (2000, p.155) salienta que, nesse modelo

\section{[...] a loucura e o sofrimento não têm de ser re- movidos a qualquer custo, eles são reintegrados como partes da existência, como elementos com- ponentes do patrimônio inalienável do sujeito.}

Yasui (2009) aponta a atenção psicossocial como o paradigma transformador da reforma psiquiátrica, visto que implica inventar um novo modelo de cuidar do sofrimento psíquico através da criação de espaços de constituição de relações sociais baseadas em princípios e valores que possibilitam reinventar a sociedade, de forma que haja um espaço para o sujeito dito louco. 
Conforme menciona Amarante (2008), é fundamental para os CAPS: oferecer estruturas flexíveis, evitando tornarem-se espaços burocratizados, repetitivos, os quais tendem a trabalhar mais em relação com a doença do que com as pessoas; propiciar o acolhimento aos sujeitos que estấo em crise e às demais pessoas envolvidas (familiares, amigos e outros), de forma que seja construída uma rede de relaçôes entre a equipe e os sujeitos que fazem parte desse contexto; realizar o trabalho terapêutico direcionado para enriquecer a existência dos sujeitos; desenvolver suas habilidades para atuar no território, ou seja, desenvolver relaçôes com os diversos recursos presentes na comunidade (associaçóes de bairro, atividades esportivas, entidades comerciais); atuar embasados no princípio da intersetorialidade, ou seja, criar estratégias que tenham interface com os diversos setores sociais, principalmente com os serviços existentes no campo da saúde mental (cooperativas, residências de egressos, unidades psiquiátricas em hospitais gerais, entre outros serviços) e da saúde em geral (unidades de saúde, Estratégia de Saúde da Família e hospitais gerais); organizar a rede de atenção aos sujeitos que passaram um longo período internados em hospitais psiquiátricos ou que estão em situação de vulnerabilidade, que precisam desenvolver autonomia, independência, enfim, necessitam de acompanhamento para realizar as atividades cotidianas e para a reinserção social; participar ativamente para que as políticas de saúde mental e atenção psicossocial organizem-se de forma que haja cooperação, sincronia de iniciativas e envolvimento dos atores sociais.

Para o fortalecimento da rede de atenção à saúde mental é necessária uma articulaçâo entre recursos econômicos, sociais, afetivos, culturais, religiosos, sanitários, que possibilitem o cuidado e a reabilitação dos sujeitos. Dessa forma, os CAPS são dispositivos que devem estar situados no núcleo da rede de serviços de saúde e em outros setores, que são fundamentais para a inserção dos sujeitos excluídos da sociedade (BRASIL, 2004a).

No Brasil, em diversas regióes, foram realizadas pesquisas sobre o trabalho nos CAPS (NUNES et al, 2010; CAMPOS et al, 2008; KANTORSKI, 2007), demonstrando que existe uma grande preocupação por parte das universidades com o trabalho desenvolvido nos mesmos, interesse que favorece o desenvolvimento e o aprimoramento da qualidade da atenção à saúde mental em nosso país. A relevância percebida nessas pesquisas incitou o desejo de investigar especificamente os CAPS de Santa Catarina, Estado que vem há algum tempo construindo sua rede de atenção à saúde mental. Imaginamos, ao empreender este estudo, que há, no contexto dessa construção continuada, um exercício constante de mudança de paradigma e invenção de novas práticas. É um processo complexo, comum no contexto da reforma psiquiátrica, que envolve mudanças de comportamento, de cultura, e que consequentemente gera insegurança e resistências. Sendo assim, existe um grande risco de continuar perpetuando a institucionalização dos sujeitos, modelo que talvez ofereça mais segurança aos profissionais que apresentam dificuldades diante de situaçóes que exigem inovaçóes não apenas na prática, mas no modo de sentir, pensar, olhar os sujeitos com sofrimento psíquico intenso.

Diante desse cenário, com intuito de conhecer o trabalho nos CAPS, esta pesquisa foi elaborada com o objetivo de analisar a percepção dos profissionais com relação à sua prática nos CAPS de Santa Catarina.

\section{Percurso Metodológico}

Trata-se de uma pesquisa de abordagem qualitativa, caracterizada como exploratória e descritiva. Definiu-se como campo da pesquisa a rede de CAPS II de Santa Catarina, em função de essa modalidade prestar atendimento especificamente aos sujeitos diagnosticados com algum 'transtorno mental' e aos egressos de hospitais psiquiátricos. Os CAPSad II (referências para pessoas que apresentam problemas relacionados ao consumo de álcool e outras drogas) e o CAPSi II (referência no atendimento de crianças e adolescentes com sofrimento psíquico) não participaram da pesquisa por atenderem a perfis específicos de usuários, suscitando temas que não se pretendia abordar neste estudo.

No Estado de Santa Catarina, à época do estudo (2011), existiam 75 CAPS, sendo 44 CAPS I, 12 CAPS II, dois CAPS III, 11 CAPSad II e seis CAPSi II 
(SANTA CATARINA, 2011a). O campo de pesquisa ficou delimitado aos 12 CAPS II, que estão distribuídos por todas as regióes do Estado.

Os participantes da pesquisa foram os coordenadores e técnicos dos 12 CAPS II de Santa Catarina. Para definir o número de profissionais e qual categoria profissional abordar, foram consideradas informaçōes da Portaria/GM no 336/02. De acordo com essa Portaria, a equipe mínima com nível superior de um CAPS II é de seis profissionais, sendo que duas categorias são definidas (médico e enfermeiro) e as outras quatro podem variar de acordo com as necessidades da unidade. Diante dessa configuração proposta pelo Ministério da Saúde, considerou-se que a participação dos 12 coordenadores e de 24 técnicos dos CAPS II - sendo dois de cada unidade - seria satisfatória para prestar as informaçóes necessárias a esta pesquisa.

Entendemos que os coordenadores não só exercem um papel fundamental na ação dos CAPS, a partir de sua liderança na esfera organizacional, mas têm também um conhecimento geral dos processos políticos, administrativos e técnicos que condicionam a ação técnico-assistencial dos serviços. Quanto à participação dos técnicos, ficou delimitada às categorias profissionais de nível superior (psicólogo, médico, assistente social e enfermeiro, entre outros) porque estes estão, de maneira geral, nas diversas unidades, diretamente em contato com os usuários e familiares, e com uma responsabilidade maior no que diz respeito ao trabalho de atendimento, o que lhes aporta a obrigação de uma aproximação mais aprofundada com a realidade investigada.

Optou-se por não definir uma categoria profissional específica, por considerar-se que a interdisciplinaridade está definida como princípio estruturante da reforma psiquiátrica e, além disso, independentemente da função exercida, todos esses técnicos de nível superior possuem informaçóes importantes para a pesquisa.

Para a coleta de dados foram realizadas entrevistas semiestruturadas com os coordenadores e aplicação de questionários abertos aos técnicos graduados. Essa forma foi preferida devido à viabilidade, já que as entrevistas implicavam visitas em unidades localizadas em diversas regióes de Santa Catarina. Dessa forma, as entrevistas com coordenadores puderam ser realizadas ao mesmo tempo em que os dados eram coletados com os outros profissionais. Os participantes foram designados por números de 01 a 35 , indiferentemente de serem coordenadores ou profissionais. Assim, os dados apresentados não diferenciam sua origem de acordo com a função ocupada, pois não era objetivo deste artigo apresentar as diferenciações de percepçóes ou compará-las, mas colher um apanhado geral das percepçóes dos profissionais, em funçóes administrativas e técnicas, com relação a suas práticas, ou seja, descrever e explorar, fundamentalmente, o funcionamento do trabalho profissional nos CAPS, na visão desses profissionais.

Para a realização das entrevistas semiestruturadas, foi elaborado um roteiro, utilizando-se das as mesmas questóes contidas no roteiro para a formulação dos questionários abertos. Antes das entrevistas e da aplicação dos questionários, foi assinado pelos participantes o "Termo de Consentimento Livre e Esclarecido", conforme a Resolução no 196/96 do Conselho Nacional de Saúde. O projeto desta pesquisa foi aprovado pelo Comitê de Ética em Pesquisa com Seres Humanos da Universidade Federal de Santa Catarina por meio do processo no 1004/367298.

Os dados das entrevistas e dos questionários geraram três categorias: 1) Atendimentos nos CAPS II; 2) Articulação dos CAPS II junto à rede de saúde; e 3) Atividades intersetoriais no território. A categoria 1 gerou, ainda, três subcategorias vinculadas à categoria principal: 1.1) Atenção à Crise; 1.2) Projeto Terapêutico Singular e Profissional de Referência; e 1.3) Oficinas e Grupos. Na categoria 2, formulamos quatro subcategorias: 2.1) Atenção Básica de Saúde; 2.2) Serviço de Atendimento Móvel de Urgência - SAMU; 2.3) Leitos Psiquiátricos em Hospital Geral; e 2.4) Serviços Residenciais Terapêuticos (SRT). Já na categoria 3, não encontramos necessidade de subdivisão, portanto, ela é apresentada de forma monolítica.

Os relatos apresentados no texto são transcrições literais das entrevistas e recortes dos questionários, os quais foram analisados sob a ótica do pensamento hermenêutico-dialético, a partir das obras de Habermas (2009), Gadamer (2002) e Stein (1987). Essa abordagem propóe compreender a realidade 
em transformação dentro de um contexto histórico e preconiza, ainda, a análise de conteúdos implícitos e explícitos.

A análise foi desenhada conforme uma perspectiva hermenêutico-dialética a que nos referimos como 'Percurso Analítico'. O tratamento dos dados empíricos foi realizado com base na interpretação, na compreensão, no consenso, na contradição e na superação dialética, que formam um 'Circuito de Análise'. Durante o trajeto no circuito analítico, surgem reflexóes, críticas, sínteses que constituem o 'filtro' do pesquisador, ou seja, não há neutralidade em quem analisa os dados. Somente depois de passar pelo percurso é que se chega a um 'Resultado Inacabado', que significa uma conclusão deste estudo, mas que é tomada como em constante transformação.

\section{Resultados e Discussão}

\section{Atendimentos nos CAPS} Atenção à Crise

$\mathrm{Na}$ atenção à crise, no contexto da saúde mental e atenção psicossocial, é necessário considerar a articulação de diversos fatores, inclusive à rede de suporte, que incluem familiares e amigos, entre outras pessoas ligadas ao indivíduo que se apresenta como protagonista na crise. Algumas pessoas podem fazer parte do processo que determina ou facilita a emergência da crise, sendo até desconhecidas do sujeito. A crise é considerada por Amarante (2008) como uma condição mais social do que biológica ou psicológica, podendo denunciar a pouca solidariedade entre as pessoas ou uma situação precária no que se refere à existência de recursos para tratamento no território ou domiciliar.

Percebe-se, através dos relatos, que em alguns serviços é realizada a tentativa de acolher o usuário em crise para que ele possa superar esse momento difícil e manter o tratamento no CAPS. Entretanto, a prática predominante adotada nas situaçóes de atendimento à crise nos CAPS de Santa Catarina ainda segue o modelo clássico da psiquiatria, centrado no controle dos sintomas de crise. Considerado complexo e difícil para a maioria dos profissionais, o atendimento à crise vinculado ao controle do sujeito usa como principais artifícios a contenção, a medicação e, principalmente, a internação em hospitais. Os profissionais entrevistados para este estudo destacam o grande esforço envidado para evitar a crise através do tratamento nos CAPS. Uma vez que o sujeito entra em crise, os profissionais demonstram dificuldades de lidar com essa situação, ressentindo-se da falta de médicos e demais profissionais habilitados a acolher esse sujeito nessas circunstâncias. "Os CAPS não são super CAPS, a equipe não tem uma varinha mágica: Agora, pronto, tirou os usuários da crise!" (Part. 5). Como reflexo dessas dificuldades, a maioria dos casos é encaminhada para internação em prontoatendimento, em hospitais gerais ou psiquiátricos.

Os profissionais reconhecem seu despreparo para atender as situaçóes de crise, e que isso gera, neles mesmos, insegurança, medo e dificuldades para desenvolver seu trabalho nessa instituição designada para atender um público sempre sujeito a, em qualquer momento, desencadear uma crise. A crise, portanto, não atinge apenas o usuário, que sofre intensamente com a falta do acolhimento à sua crise, mas também à saúde mental dos profissionais.

O que emerge como aparente é que os CAPS dão conta dos usuários que se encontram estabilizados, a maioria medicada. Lidar com a crise exige mais preparo, coisa que os profissionais alegam não possuir, o que demonstra a necessidade de investimento na capacitação dos recursos humanos já existentes e na seleção de profissionais para trabalhar nos CAPS.

\section{Projeto Terapêutico Singular e Profissional de Referência}

Projeto Terapêutico Singular é um plano de tratamento a ser realizado pela equipe do CAPS, especificamente para cada usuário. Trata-se de um conceito emergente no contexto da reforma psiquiátrica, colocado como dispositivo para a superação dos tratamentos tradicionais, que massivamente aplicavam intervençóes medicamentosas, na maioria das vezes, ignorando a singularidade dos sujeitos, as necessidades específicas não só de medicaçóes, mas também de outras formas terapêuticas. Em dez CAPS, detectou-se a existência de Projetos 
Terapêuticos Singulares, os quais são discutidos nas reuniōes de equipe. Nos outros dois CAPS, os profissionais responderam que ainda estão em processo de implantação do Projeto Terapêutico Singular.

O termo Profissional de Referência refere-se, em geral, àquele profissional que tem uma relação mais 'próxima' com o usuário e que, baseado nessa proximidade contingencial, potencializa sua ação terapêutica. Em cada CAPS de Santa Catarina essa prática acontece de forma relativamente diferente, conforme a dinâmica do serviço. Em quatro CAPS, um profissional de referência é designado para cada usuário. Em um CAPS, o profissional de referência passa a ser aquele com quem o usuário mais se identifica, independentemente, inclusive, da formação desse profissional. Neste caso, o profissional de referência pode ser a cozinheira, o jardineiro, a psicóloga, o médico etc. Em outros quatro CAPS, estabeleceu-se que qualquer profissional da equipe na qual o usuário participa das atividades é um profissional de referência. Em um CAPS, o profissional de referência é aquele que avalia as condições para o usuário receber alta do tratamento. No caso do usuário precisar novamente da assistência do CAPS, poderá procurar esse profissional. Em um dos serviços, a equipe náo conseguiu implantar o profissional de referência. Em outro, o trabalho com profissional de referência não obteve êxito no atendimento dos usuários, conforme relatado, porque quando esse profissional não estava presente no CAPS, os outros profissionais se negavam a atender o usuário por considerarem que isso não era sua responsabilidade. Então, para facilitar o atendimento dos usuários, foi extinto, naquele serviço, o trabalho com profissionais de referência.

A existência de Projeto Terapêutico Singular e de Profissional de Referência é fundamental para o acompanhamento do usuário durante o tempo em que ele é atendido no CAPS. Esses dispositivos podem ser considerados como indicativos da qualidade do processo de cuidado, assim como do nível de relacionamento entre os profissionais da equipe. Além disso, são fatores que, quando bem conduzidos, podem proporcionar ao usuário a segurança de que está sendo acolhido, atendido e cuidado com interesse, respeito e eficácia pela equipe. No caso do Profissional de Referência, quando cumpre efetivamente seu papel, o usuário tem a segurança de que poderá contar, a qualquer momento, com a equipe do CAPS.

\section{Oficinas e Grupos}

As oficinas e grupos terapêuticos são algumas das principais formas de tratamento nos CAPS. Essas atividades são coordenadas por um ou mais profissionais, e podem ser definidas a partir das necessidades dos usuários e das disponibilidades de técnicos, com o objetivo de promover a integração social e familiar, a expressão dos sentimentos e dificuldades, o desenvolvimento de habilidades pessoais e laborais, e o exercício da cidadania (BRASIL, 2004a). As práticas de grupos e oficinas fazem parte do cotidiano dos profissionais e usuários dos CAPS.

Para Barros (2009), o atendimento em grupos e oficinas é uma estratégia para promover uma nova assistência em saúde mental, por ser alternativa ao modelo tradicional de tratamento psiquiátrico. Essa composição de sujeitos visa, entre outras finalidades, à troca de experiências e à formação de vínculos, aspectos fundamentais para a ressocialização e a reabilitação social. Alguns profissionais salientam que os grupos produzem efeitos como desconstrução de cristalizações, invenção de alternativas existenciais e oportunidade de compartilhar sofrimentos. Nesse modelo de atendimento, é possível atender maior número de pessoas ao mesmo tempo, aspecto considerado importante sob o ponto de vista da viabilidade, no contexto do Sistema Único de Saúde (SUS).

No decorrer das visitas aos CAPS de Santa Catarina, observou-se que as práticas de grupos e oficinas, no formato aberto ou fechado, são realizadas diariamente, com diversos objetivos terapêuticos, tais como: desenvolver habilidades; melhorar a autoestima; promover autonomia; exercer a cidadania, o autoconhecimento, a reinserçâo social, o lazer, a educação em saúde; discutir questóes relacionadas à medicação e à integração dos familiares ao tratamento etc. Em cada CAPS, há uma dinâmica diferente de trabalho, com diferentes propostas de oficinas e grupos. De forma geral, nos CAPS de Santa Catarina as oficinas estão mais relacionadas ao 
exercício da cidadania, com atividades voltadas para a produtividade, como a confecção de artesanatos, costura, tapeçaria e culinária. Também envolvem o uso de formas artísticas como meio de expressão, como teatro, dança e música, entre outras. Já o termo "grupo" é utilizado com um enfoque mais relacionado ao tratamento do sujeito, conforme seu diagnóstico. Existem, por exemplo, grupos específicos para usuários com esquizofrenia, outros para usuários diagnosticados com depressão e alguns mais gerais, como os grupos antitabagismo, voltados para reduzir o consumo de cigarros.

O engajamento dos usuários na construção das oficinas e dos grupos é fundamental para atingir os propósitos desses trabalhos, pois é através dessa participação que eles vão se envolvendo em processos de ação coletiva e superando suas dificuldades. Os profissionais relataram que a vontade de participar, por parte dos usuários, é bem dividida: uns gostam de participar e outros, nem tanto.

A falta de recursos financeiros para a realização das oficinas é mencionada em alguns CAPS, o que resulta no empobrecimento dessa atividade. Os profissionais mencionaram, entretanto, experiências exitosas principalmente com relação aos grupos. Contar o sucesso, para esses profissionais, é expor vitórias em meio a várias tentativas e a muito trabalho. Algumas equipes dos CAPS, com o apoio dos gestores e da sociedade civil, superaram as dificuldades financeiras, colocando em prática um sistema de atividades economicamente autossustentáveis. A falta de recursos financeiros para as oficinas demonstra que, em alguns municípios, não há investimento para as atividades voltadas para a saúde mental.

\section{Articulação dos CAPS com a Rede de Saúde}

A articulação dos CAPS para a construção de uma rede de atenção à saúde mental de base territorial é fundamental para o desenvolvimento do sistema de saúde. Para os usuários, a construção contínua dessa rede é essencial, pois, na base de sua inserção social e comunitária estão os recursos existentes na comunidade, que podem definir como esses usuários se sentirão em termos de sua inserção e de seu acolhimento.
A consolidaçáo da atençáo psicossocial é essencialmente ligada, portanto, aos demais serviços de saúde e à rede de recursos comunitários, no sentido de que estes possam atender e acolher os usuários dos CAPS, formando, assim, uma rede que ofereça cuidados às pessoas com sofrimento psíquico. Neste trabalho, são citados os serviços mencionados nos CAPS e aqueles que são destinados pelo Ministério da Saúde para atuar junto aos CAPS.

\section{Atenção Básica de Saúde}

A construção de uma nova forma de atender as pessoas com sofrimento psíquico intenso requer que o CAPS e a Atenção Básica de Saúde estejam integrados, viabilizando o trabalho em saúde mental no território. A proposta do Ministério da Saúde é que esta integração possibilite que o CAPS possa conhecer e interagir com as equipes de atenção básica do território; verificar os problemas e necessidades de saúde mental e adotar iniciativas em conjunto; realizar apoio matricial às equipes da atenção básica; e desenvolver atividades de educação permanente sobre saúde mental em parceria com os profissionais da atençâo básica. $\mathrm{O}$ apoio matricial ou matriciamento significa o suporte às equipes da atenção básica por meio de orientação e supervisão, atendimento em conjunto de situaçôes complexas e visitas domiciliares, ou seja, a responsabilidade compartilhada dos casos. Vale ressaltar que esse trabalho é diferente da lógica da referência e contrarreferência, que ficam restritas aos encaminhamentos (BRASIL, 2004a).

Em nove CAPS visitados, foi relatado que a atençấo básica absorve uma parte da demanda de usuários com problemas relacionados à saúde mental, porém, com algumas dificuldades. Um dos problemas apontados e considerados como dos mais preocupantes foi a estigmatização dos usuários dos CAPS e, ao mesmo tempo, a falta de preparo dos profissionais da atenção básica para trabalhar com esse público. Esses dois fatores combinados resultam na resistência do próprio usuário a ser atendido na atenção básica. Nos outros três CAPS, não há equipe preparada para absorver os usuários do CAPS nem profissional de saúde mental na atenção básica dos municípios. 
Segundo os participantes, essas dificuldades dos profissionais da atenção básica em relação à saúde mental vêm sendo superadas através de capacitações e, principalmente, do matriciamento. Em cinco CAPS, foi relatado que o matriciamento já está funcionando de forma efetiva, apresentando bons resultados. Nos demais CAPS, foi mencionado que estáo iniciando o processo para realizar o matriciamento, com exceção de um CAPS em que o matriciamento ainda está muito distante da realidade do município.

Percebe-se, através dos depoimentos, que os CAPS de Santa Catarina vivem realidades bem distintas em relação ao suporte da atenção básica. Em alguns municípios, passa-se pela Unidade de Saúde antes de ir para o CAPS. Geralmente, nos casos de internação, os usuários são encaminhados direto para os CAPS. Já em outros municípios, o CAPS funciona como porta de entrada, em função da dificuldade de manejo dos profissionais na Unidade Básica de Saúde. Segundo um profissional, em seu município:

Chorou na Unidade de Saúde, vai para o CAPS. Se falou que é cliente de CAPS, vem para cá [para o CAPS]. A porta de entrada era o CAPS [...] estamos revendo isso. Com o matriciamento, deve dar uma melhorada. (Part. 04).

O fato de haver um primeiro atendimento na atenção básica nem sempre é um facilitador para a assistência em saúde mental. Na verdade, isso pode se constituir, por si, em um problema, caso o CAPS seja uma instituição de "portas fechadas", como é o exemplo de um município de Santa Catarina:

Para ser atendido no CAPS, é necessário passar pela unidade de saúde e depois é (sic) encaminhado para uma avaliação com o psiquiatra. Somente os casos de tentativa de suicídio e crise psicótica são encaminhados para o CAPS. O problema é que existe uma fila de 500 pessoas esperando para serem pacientes de CAPS. A atenção básica não tem equipe de saúde mental. O CAPS não atende demanda espontânea.
Busca-se mudar esse modelo de atendimento, mas há resistência. (Part. 10).

Observa-se que a falta de flexibilidade na dinâmica do atendimento aumenta o risco das estruturas ficarem engessadas, de maneira que o usuário não consiga circular na rede de assistência à saúde e, consequentemente, seja prejudicado no que diz respeito à sua saúde mental e aos seus direitos de cidadão.

\section{Serviço de Atendimento Móvel de Urgência - SAMU} O SAMU é um serviço de saúde responsável pela parte de regulação dos atendimentos de urgência, pelo atendimento móvel de urgência e pelas transferências de pacientes graves da região. É capaz de atender, dentro da regiáo de abrangência, qualquer pessoa em situação de urgência ou emergência, e transportá-la com segurança e acompanhamento de profissionais da saúde até um hospital (SANTA CATARINA, 2011b).

O Ministério da Saúde, em 2004, realizou a primeira Oficina de Atenção às Urgências e Saúde Mental, com o objetivo de promover o diálogo e a articulação entre a Política Nacional de Atenção às Urgências e a Política Nacional de Saúde Mental. Essa oficina ocorreu devido à necessidade da articulação entre a rede de atenção à saúde mental e as equipes do SAMU, para o fortalecimento e a ampliação das açóes de saúde mental no SUS. O SAMU, a partir dessa oficina, assumiu, em conjunto com a área de saúde mental, a responsabilidade pelo atendimento às urgências psiquiátricas e pelo fomento à implantação de CAPS e de serviços de urgências em hospitais gerais nos municípios onde está implantado. Foi estabelecido também o compromisso de apoio da rede CAPS à rede SAMU, a ser materializado de forma matricial e incluir supervisão, capacitação continuada, atendimento compartilhado de casos e apoio à regulação (BRASIL, 2007).

No SAMU de Santa Catarina, foi instituída a regulação da assistência, visando a priorizar as necessidades de saúde da populaçáo, buscando racionalizar os recursos existentes, propiciando o atendimento de acordo com a necessidade, seguindo o princípio doutrinário do SUS da equidade. Os atendimentos do SAMU são 
realizados mediante Protocolos de Regulação, dentre estes, os Protocolos de Regulação da Atenção Pré-Hospitalar Móvel, que contemplam a 'Regulação em Saúde Mental' e a 'Tentativa de Suicídio', e os Protocolos de Regulação das Transferências Inter-Hospitalares, responsáveis pelas 'Emergências em Psiquiatria' (SANTA CATARINA, 2011b).

Com relação aos serviços prestados pelo SAMU, de atendimento às solicitaçóes dos CAPS em Santa Catarina, foi mencionado, em quatro CAPS, que o SAMU não atende resgate de usuários do CAPS; em cinco CAPS, a solicitação do atendimento ao SAMU, quando aceita, acontece com muita dificuldade; e apenas em três CAPS foi mencionado que o SAMU atende os chamados dos CAPS, alternando o resgate com a Central de Ambulância ou o Corpo de Bombeiros.

A maioria dos relatos aponta contundentemente o descaso e o preconceito no atendimento do SAMU para com os usuários dos CAPS. Diante desse problema, é necessário recorrer a outros recursos, conforme menciona um profissional:

Quando o paciente está agressivo, não tem jeito, é a polícia que vai. [...]. A polícia só vai se tiver internação garantida. O SAMU, para levar paciente em crise, é muito difícil. (Part. 02).

A resposta de um profissional do SAMU, 'Se é louco, eu não vou' (Part. 10), em um caso de uma solicitação do CAPS, é relatada por um participante da pesquisa, representando a dificuldade de estabelecer uma parceria com aquele serviço, em função da estigmatização sofrida pelos sujeitos com sofrimento psíquico intenso.

\section{Leitos Psiquiátricos em Hospital Geral}

A proposta de implantação de leitos psiquiátricos em hospitais gerais tem como objetivo oferecer acolhimento integral ao sujeito que está em crise. Esse serviço deve estar articulado com os outros dispositivos da rede de saúde mental comprometidos com o cuidado desse usuário.
É flagrante a falta de leitos psiquiátricos em hospitais gerais de Santa Catarina, o que ilustra as dificuldades para implantação desses leitos nos hospitais. Os problemas envolvem também outros fatores, conforme revelam os profissionais do CAPS:

Há leitos em hospital geral, mas é muito difícil conseguir internação, uma vaga para esses supostos leitos. [...] Temos dois hospitais, pela lógica não deveríamos ter essa dificuldade [...], um deles com oito leitos, mas a gente percebe que é mais no discurso do que na prática. Os leitos são cedidos para outras especialidades, internaçôes de planos de saúde, outras situações. [...] O hospital coloca dificuldade da equipe deles de atendimento, dificuldade de não ter uma ala e ser leito em hospital geral, [...] sempre tem alguma desculpa. (Part. 10).

Foi mencionado um hospital geral público em que os leitos foram fechados em função da cobrança de consulta médica antes da internação. Outros hospitais também foram mencionados por essa mesma prática:

Tem alguns lugares que os médicos psiquiatras vendem os leitos, só tem leito se pagar $R \$$ 280,00. Aí, nós não mandamos. [...] O médico cobra uma consulta para colocar no leito do SUS. (Part. 07).

O profissional menciona que esse hospital já foi denunciado pelo CAPS, no entanto, a resposta foi que, devido à falta de psiquiatra no interior do Estado, é muito difícil resolver essa situação. Ele acrescenta: "O Estado deixa assim porque não tem o que fazer" (Part. 07).

Percebe-se que os problemas vão muito além da resistência à implantação, pois, em alguns municípios, as dificuldades estão na implementação do serviço. Vale salientar que esses hospitais estão em diferentes regióes do Estado, o que demonstra náo ser um fato isolado.

O 'Dicionário de Política' (BOBBIO, 1998, p. 293) define corrupção como "o fenômeno pelo qual um funcionário público é levado a agir de modo diverso dos 
padrốes normativos do sistema, favorecendo interesses particulares em troca de recompensa”. A corrupção tem sido objeto de muita atenção no Brasil, onde as estruturas democráticas estáo ainda vulneráveis e sujeitas a atuações políticas, jurídicas e técnicas aplicadas de formas viciosas, com base nas estruturas de poder herdadas das tradições coloniais. A corrupção na área da saúde é também objeto de preocupação e, conforme os depoimentos dos profissionais acima, parece ser legitimada e, algumas vezes, considerada natural, como parte de um contexto normalizado. Alguns dos fatos relatados pelos participantes desta pesquisa foram denunciados em encontros públicos, o que leva a pensar que, em alguns casos, em Santa Catarina, as autoridades parecem acuadas, impotentes ou coniventes com os fatos, os quais fazem parte do complexo sistema de intervenção e terapêutica em saúde mental e atenção psicossocial.

\section{Serviços Residenciais Terapêuticos (SRT)}

Os SRTs são casas situadas no espaço urbano, integradas à comunidade, com o objetivo de atender às necessidades de moradia dos sujeitos com 'transtornos mentais graves'. São destinadas aos indivíduos que passaram por longas internaçôes psiquiátricas, egressos de Hospitais de Custódia e usuários dos CAPS que são moradores de rua ou em relação aos quais a equipe identifica problema de moradia (BRASIL, 2004b). Nessas situaçôes, é avaliado se houve ruptura dos vínculos familiares ou sociais. Esse serviço tem o intuito de oferecer melhores condiçóes de vida, possibilidades de retorno ao convívio social e garantia dos direitos sociais a esses sujeitos.

Em 2011, foram implantados dois SRTs em um município no norte do Estado de Santa Catarina. Os outros três SRTs existentes em Santa Catarina estão localizados próximo ao Instituto Psiquiátrico de Santa Catarina (IPq), complexo hospitalar psiquiátrico situado em uma região onde não existem CAPS. Os profissionais do IPq trabalham com aos moradores desses SRTs, que anteriormente estavam internados no próprio hospital. Em função dessas moradias estarem diretamente vinculadas a um hospital psiquiátrico, questiona-se se realmente deveriam ser consideradas como SRTs.
A maioria dos profissionais mencionou a necessidade da existência de SRTs em seus municípios, em função das pessoas que estão ainda morando em hospitais psiquiátricos ou hospitais de custódia, e que poderiam, caso houvesse esse apoio, participar de algum programa de desinstitucionalização. Situação similar é apontada com relação a usuários que são moradores de rua, usuários que estão na rua em consequência de conflitos com seus familiares e um grande contingente de sujeitos em situação de rua relacionada à dependência de álcool e outras drogas.

Um profissional manifestou receio à implantação dos SRTs em seu município devido ao entendimento dos gestores com relação a esse serviço. Teme que as residências sejam utilizadas para outros objetivos e não para o que realmente são destinadas pelo Ministério da Saúde. Pensa também que esses serviços correriam, neste caso específico, o risco de tornarem-se pequenos manicômios ou simples abrigos para usuários que apresentam dificuldades de convivência com os familiares e dependentes de álcool e outras drogas.

Alguns municípios buscam formas alternativas aos SRTs para abrigar usuários que estão em situação de rua, como asilos, projetos em que as famílias recebem algum benefício para acolherem o usuário e instituiçôes de abrigamento temporário, como as Casas de Passagem.

Percebe-se que existe um entendimento por parte dos profissionais de que ocorrem divergências entre os objetivos dos SRTs em funcionamento com as propostas explicitadas pelo Ministério da Saúde, voltadas essencialmente para a desinstitucionalização dos sujeitos atendidos, o que, sob a ótica desses profissionais, dificulta a implantação de tais dispositivos. O fato é que a implantação dos SRTs em Santa Catarina caminha vagarosamente, não se revelando, de nenhuma forma, como um foco para os gestores da saúde.

\section{Atividades Intersetoriais no Território}

Os CAPS devem atuar no território (geográfico, político, econômico e cultural) desenvolvendo parcerias com os diversos recursos existentes na comunidade, trabalhando de forma intersetorial. Os dispositivos 
existentes no território abrangem, na maioria dos municípios catarinenses, além da rede de atenção à saúde, as secretarias de educação, de cultura, de ambiente, associações civis, instituiçóes filantrópicas, empresas, enfim, parceiros que possam contribuir para a inclusão social dos sujeitos com sofrimento psíquico.

A intersetorialidade, segundo Junqueira (1997, p. 37), é a

\section{[...] articulação de saberes e experiências} no planejamento, realizaçâo e avaliação de açöes para alcançar efeito sinérgico em situaçóes complexas visando o desenvolvimento social, superando a exclusão social.

Nas entrevistas e nos questionários, os profissionais mencionaram poucas açôes de parcerias dos CAPS com organizaçóes onde os usuários possam envolver-se ativamente e em caráter contínuo. As instituições mencionadas pelos profissionais como parceiras apenas aceitam encaminhamentos de usuários dos CAPS para participação em cursos, grupos e agendamento de consultas.

Supostamente, esses locais, que proporcionam atividades e atendimento psicossocial para a comunidade, naturalmente deveriam aceitar qualquer pessoa, tomando uma postura eminentemente não discriminatória, inclusive, sem a necessidade de um encaminhamento específico. Entretanto, a realidade é que os CAPS precisam construir 'parcerias' com essas instituiçóes para que elas aceitem atender seus usuários. Provavelmente, o fato de outras instituiçóes não aceitarem os usuários faz com que aquelas que atendem os encaminhamentos sejam consideradas 'parceiras'.

A partir do conceito de intersetorialidade de Junqueira (1997), acima mencionado, pode-se dizer que os CAPS, em Santa Catarina e de modo geral, não atuam de forma intersetorial, o que dificulta bastante a inserção social dos usuários.

\section{Considerações Finais}

Diante do cenário apresentado pelos profissionais, percebe-se que a rede de CAPS dos municípios de Santa Catarina atravessa um momento de muitas dificuldades e têm-se encontrado, para estas, poucas soluçóes. Tais dificuldades estão relacionadas à falta de apoio, de investimento, e, principalmente, de entendimento por parte dos gestores com relação à atenção psicossocial. No Estado de Santa Catarina, não existem dispositivos (cooperativas, centros de convivência, outros tipos de organizaçôes) para a reinserção social dos sujeitos com sofrimento psíquico intenso. A deficiência da articulação entre os CAPS e os demais serviços de saúde, em todos os níveis de atenção, é uma questão crucial, que tem como efeito o retrocesso do processo de reforma sanitária no âmbito da saúde mental. Nessas circunstâncias, o papel do CAPS de organizador da rede de cuidados, conforme preconiza o Ministério da Saúde, fica totalmente comprometido.

A situação atual de Santa Catarina induz os CAPS a trabalharem no limiar da institucionalização, uma vez que os usuários não têm suporte necessário para uma progressão no processo de aquisição de mais autonomia fora das instituiçóes que prestam assistência à saúde mental. Do mesmo modo, a ausência de açóes intersetoriais prejudica enormemente os esforços de outra forma envidados para a melhoria da qualidade de vida dos usuários dos CAPS, tendo sido apontada, neste estudo, como imprescindível para a construçáo da rede de atenção à saúde mental. As principais observaçôes e sugestôes colhidas nesta pesquisa mostram um grau de compreensão, por parte dos profissionais entrevistados, que permite afirmar que há necessidade premente e urgente de transformação do cenário catarinense no que tange ao cuidado em saúde mental e à atenção psicossocial. E, certamente, a partir destas observaçôes e sugestóes, talvez o Estado de Santa Catarina possa dar um salto de qualidade nesse campo, no que concerne à efetividade, à eficácia e à eficiência de seu sistema de saúde. 


\section{Referências}

AMARANTE, P. Loucos pela Vida: a trajetória da Reforma Psiquiátrica no Brasil. 2 ed. Rio de Janeiro: ENSP/FIOCRUZ, 1998. 132 p.

Saúde Mental e Atenção Psicossocial. Rio de Janeiro: FIOCRUZ, 2008. 120p.

BOBBIO, N. et al (org.). Dicionário de Política. 11. ed. Brasília: Ed. Universidade de Brasília, 1998. 666p. v. I.

BARROS, R. B. B. Subjetividades contemporâneas, dispositivo grupal e saúde mental. In: CARVALHO, S. R. et al (org.). Conexões: saúde coletiva e políticas da subjetividade. São Paulo: HUCITEC, 2009. p.

BRASIL. Ministério da Saúde. Portaria no 3.088/GM , de 30 de dezembro de 2011. Brasília: Ministério da Saúde, 2011. Disponível em: <http:// www.brasilsus.com.br/legislacoes/qm/111276-3088.html>. Acesso em: 14 maio 2012.

Ministério da Saúde. Portaria no 336/GM, de 19 de fevereiro de 2002. Brasília: Ministério da Saúde, 2002. Disponível em: <http://portal. saude.gov.br/portal/arquivos/pdf/Portaria\%20GM\%20336-2002.pdf > Acesso em: 10 jun. 2009.

Ministério da Saúde. Portaria no 224/MS, de 29 de janeiro de 1992. Brasília: Ministério da Saúde, 1992. Disponível em: <http:// www.saude.mg.gov.br/atos_normativos/legislacao-sanitaria/ estabelecimentos-de-saude/saude-mental/PORTARIA_224.pdf> Acesso em: 10 jun. 2009.

Presidência da República. Lei no 10.216, de 06 de abril de 2001. Brasília: Presidência, 2001. Disponível em: <http://www.planalto.gov. br/ccivil/LEIS/LEIS_2001/L10216.htm> Acesso em: 10 junho 2009.

Ministério da Saúde. Secretaria de Atenção à Saúde. Departamento de Ações Programáticas Estratégicas. Saúde Mental no SUS: os Centros de Atenção Psicossocial. Brasília: Ministério da Saúde, 2004a. 86p.

Ministério da Saúde. Secretaria de Atenção à Saúde. Departamento de Ações Programáticas Estratégicas. Residências terapêuticas: o que são, para que servem. Brasília: Ministério da Saúde, 2004b. 20p.

- Ministério da Saúde. Secretaria de Atenção à Saúde/DAPE. Saúde Mental no SUS: acesso ao tratamento e mudança do modelo de atenção: Relatório de Gestão 2003-2006. Brasília: Ministério da Saúde, 2007.78p.

CAMPOS, R. O. et al (org). Pesquisa Avaliativa em Saúde Mental: Desenho Participativo e Efeitos da Narratividade. São Paulo: Aderaldo \& Rothschild, 2008. 428p.

COSTA-ROSA, A. O. Modo Psicossocial: um Paradigma das Práticas Substitutivas ao Modo Asilar. In: AMARANTE, P. D. C. (org.). Ensaios:
Subjetividade, Saúde Mental, Sociedade. Rio de Janeiro: FIOCRUZ, 2000. 314p.

GADAMER, H. G. Verdadee método Il:complementos e índice. Petrópolis: Vozes, 2002.621p.

HABERMAS, J. A Lógica das ciências sociais. Petrópolis : Vozes, 2009. 336p.

JUNQUEIRA, L. A. P. Novas formas de gestão na saúde: descentralização e intersetorialidade. Revista Saúde e sociedade, São Paulo, v. 6, n. 2, p. 31 46, 1997.

KANTORSKI, L. P. (coord.). Avaliação dos CAPS da Região Sul do Brasil CAPSUL. Pelotas: CNPq, Ministério da Saúde, 2007.

NUNES, M. O. et al. A articulação da experiência dos usuários nas microculturas dos Centros de Atenção Psicossocial - uma proposta metodológica. Estudos e Pesquisas em Psicologia UERJ, Rio de Janeiro, a. 10, n. 1, p. 204-220, jan./abr. 2010. Disponível em: <http://www.revispsi. uerj.br/v10n1/artigos/pdf/v10n1a14.pdf.>. Acesso em: 14 jun. 2010.

OLIVEIRA, W. F. Éticas em conflito: reforma psiquiátrica e lógica manicomial. Caderno Brasileiro de Saúde Mental, Florianópolis, v. 1, n. 2, p. 48-61, out./dez. 2009. Disponível em: <http://periodicos.incubadora. ufsc.br/index.php/cbsm/article/view/1126> Acesso em: 12 maio 2012.

SANTA CATARINA. Secretaria de Estado da Saúde de Santa Catarina. Saúde Mental - CAPS. Santa Catarina: Secretaria de Estado da Saúde, 2011a. Disponível em: <http://portalses.saude.sc.gov.br/index. php?option=com_content\&view=article\&id=315\&ltemid $=163>$ Acesso em: 18 jul. 2011.

Secretaria de Estado da Saúde de Santa Catarina. Apostila do SAMU. Santa Catarina: Secretaria de Estado da Saúde, 2011b. Disponível em: $\quad<$ http://samu.saude.sc.gov.br/arquivos/apostila_do_samu_ santa_catarina.pdf > Acesso em: 04 abr. 2011.

STEIN, E. Dialética e hermenêutica: uma controvérsia sobre método em filosofia. In: HABERMAS, J. Dialética e hermenêutica: para crítica da hermenêutica de Gadamer. Porto Alegre: L\&PM, 1987. p. 98-134.

YASUI, S. A atenção psicossocial e os desafios do contemporâneo: um outro mundo é possível. Caderno Brasileiro de Saúde Mental, Florianópolis, v. 1, n. 1, p. 1-9, jan./abr. 2009. Disponível em: <http:// www.cbsm.org.br/artigos/artigos/11_Silvio_Yasui.pdf> Acesso em: 06 jun. 2011.

Recebido para publicação em Outubro/2011

Versão definitiva em Junho/2012

Suporte financeiro: Não houve

Conflito de interesse: Inexistente 